\title{
Advanced nurse roles in UK primary care
}

\author{
Bonnie Sibbald, Miranda G Laurant and David Reeves
}

T he National Health Service (NHS) of England was established in 1948, with general practitioners as the principal providers of primary care and gatekeepers to other health services. This model of care has undergone substantial change. The GPs' monopoly on primary care has been broken by nurse-led services, including NHS Direct, which provides 24-hour health advice by telephone, and NHS walk-in centres, which treat minor illness and injury. Within general practice, GPs working alone have given way to large multidisciplinary teams, employing six or more doctors and a wide range of administrative and clinical staff. ${ }^{1}$ Practice nurses and nurse practitioners increasingly substitute for GPs in the care of minor illness and routine management of chronic diseases, such as asthma, diabetes and coronary heart disease. ${ }^{2}$

The same trend is found in hospital settings, where "advanced practice nurses" and "clinical nurse specialists" have extended their scope of practice into areas previously the province of doctors alone. A survey of 490 NHS Trusts conducted in 1996 found that $87 \%$ of them employed clinical nurse specialists (3191 nurses in total) while $36 \%$ employed advanced practice nurses (316 nurses in total). ${ }^{3}$ The most common areas of employment for clinical nurse specialists were cancer, diabetes, health visiting, and mental health. The most common areas of employment for advanced practice nurses were accident and emergency, mental health, ophthalmology and orthopaedics.

While it is clear that nurses are playing an increasingly prominent role in health care provision in the NHS, it is impossible to describe the exact scale and scope of this change. This is because there are no formal licensing criteria underpinning the job titles of nurse practitioner, advanced practice nurse or clinical nurse specialist. In consequence, there is no centralised information on the numbers or distribution of such staff. All such nurses will have been trained to degree level and undertaken postgraduate training in their specialist area. Many will hold a Masters degree, although this is not universal. The title "nurse practitioner" is arguably most often used to describe a registered nurse with additional postgraduate training who has lead responsibility for a defined area of health care provision in primary care. Given the difficulty of defining a nurse practitioner in the United Kingdom, we focus here on nurses working in these advanced roles in primary care whether or not they bear the title nurse practitioner.

\section{Factors driving change}

The factors motivating the extension in nursing roles are many and complex. In common with other developed countries, the NHS in England faces rising demand for health care, pressure to constrain costs, poor access to services in deprived urban areas, and medical workforce shortages. A common response to such challenges has been to extend the role of nurses into areas that were previously the domain of doctors alone. The expectation is that nurses can:

- enhance the quality of services provided by doctors;

- substitute for doctors in many areas, thus reducing demand for doctors; and

- reduce costs, as they are cheaper to employ than doctors.

In primary care, the biggest stimulus for change was brought about by the 1990 GP contract, which paid doctors to provide

\section{ABSTRACT}

- Nurses increasingly work as substitutes for, or to complement, general practitioners in the care of minor illness and the management of chronic diseases.

- Available research suggests that nurses can provide as high quality care as GPs in the provision of first contact and ongoing care for unselected patients.

- Reductions in cost are context dependent and rarely achieved. This is because savings on nurses' salaries are often offset by their lower productivity (due to longer consultations, higher patient recall rates, and increased use of tests and investigations).

- Gains in efficiency are not achieved when GPs continue to provide the services that have been delegated to nurses, instead of focusing on the services that only doctors can provide.

- Unintended consequences of extending nursing roles include loss of personal continuity of care for patients and increased difficulties with coordination of care as the multidisciplinary team size increases. Rapid access to care is, however, improved.

- There is a high capital cost involved in moving to multidisciplinary teams because of the need to train staff in new ways of working; revise legislation governing scope of practice; address concerns about legal liability; and manage professional resistance to change.

- Despite the unintended consequences and the high costs, extending nursing roles in primary care is a plausible strategy for improving service capacity without compromising quality of care or health outcomes for patients.

MJA 2006; 185: 10-12

For editorial comment, see page 8

chronic disease clinics and to meet population target rates for vaccinations and cervical screening. GPs responded by employing nurses to provide these services. ${ }^{4}$ The larger practices were better able to find the money and other resources needed to extend nursing roles, and those practices which enhanced their skill mix in this way were best able to meet the new performance targets. ${ }^{5-7}$ Thus, economies of scale accelerated the growth in multidisciplinary team size and complexity.

This momentum is likely to be sustained and enhanced by the most recent GP contract of 2004. The contract is centred on the practice, not the individual GP, and a substantial proportion of the payment is linked to the attainment of quality of care targets for a range of common clinical conditions. This will provide a further impetus to the substitution of doctors by nurses in the management of minor illness, and the expansion of specialist roles for nurses, particularly in the management of chronic conditions, such as asthma, diabetes and heart disease.

\section{Evidence for nurse effectiveness and efficiency}

The results of a recent systematic review of the available research into nurse-doctor substitution suggests that, in the provision of first contact and ongoing care for unselected patients, nurses can 
provide as high quality care as GPs. ${ }^{8}$ Indeed, nurse-led care was in some respects superior to that of doctors in that nurses tended to give patients more information and patients were more likely to be satisfied. No aspects of care were identified in which doctors performed better than nurses. However, research to date has rigorously evaluated only a small part of the wide range of care that nurses provide.

Surprisingly few studies have been conducted into whether nurse-doctor substitution saves money or reduces doctors' workload, but the available research suggests these gains are rarely achieved. This is because doctors may continue to provide the same services as nurses, leading to duplication rather than substitution of care. ${ }^{9}$ Efficiency gains are possible only if active steps are taken to make doctors discontinue the services delegated to nurses and focus instead on the tasks that only doctors can perform. ${ }^{10}$ In most studies, savings on nurses' salaries were offset by their lower productivity (due to longer consultations, higher patient recall rates and increased use of tests and investigations), leading to no overall reductions in cost. However, as salary differentials and productivity vary from place to place, cost savings are context dependent and may be achieved in some situations.

Health promotion is another of the principal areas of work in which nurses take the lead in delivering services. In most British general practices throughout the 1990s, nurses were responsible for carrying out well-patient health checks and providing lifestyle and other interventions in accordance with agreed treatment guidelines. ${ }^{2}$ Two large-scale randomised controlled trials showed that nurses were highly effective in screening patients and delivering appropriate health promotion advice, although the health gains for patients did not justify the costs. ${ }^{11,12}$

The situation is more promising in other aspects of health promotion, such as cervical screening and childhood vaccinations. Here, there is good evidence from controlled trials that these activities are cost-effective in generating health gains for patients. Most of this health promotion work is organised and delivered by nurses, not doctors; and gains made in reducing inequalities in health and health care provision in England over the 1990s were achieved largely through the introduction of these nurse-led services. $^{13,14}$

Research shows also that nurses are highly effective in managing chronic diseases. ${ }^{15}$ The key element of effective care is service organisation. If care is well structured (ie, there is a patient register and recall system, with clinical reviews conducted in accordance with evidence-based guidelines), then health outcomes for patients are good. General practice diabetes clinics have been shown to provide as high quality care as hospital outpatient clinics when they are well structured. ${ }^{16}$ In coronary care, nurse-led specialist clinics appear to be as effective as doctor-led specialist clinics, and more effective than care provided by doctors in routine consultations. ${ }^{17,18}$ In other words, the evidence suggests that nurse-led chronic disease clinics offer higher quality clinical care than can be achieved by GPs in conventional practice.

\section{Unintended consequences}

There are, of course, unintended impacts of increasing team size and complexity.

Larger team size is a logical consequence of integrating nurses into primary care teams. As the number of staff in a team increases so do "transaction costs". People need to spend increasing amounts of time conferring with each other, decreasing the amount of time available for direct patient care. As team size increases, a critical point is reached where transaction costs can outweigh the benefits of collaboration. ${ }^{19}$ Measuring transaction costs, however, is not easy, and existing research has little to offer by way of guidance on optimal team size. One study suggests team sizes should not exceed 10 people, but further research is needed to test the validity of this finding. ${ }^{19}$ Shared patient record systems, which all team members may contribute to and withdraw information from, have been advocated as one means of reducing transaction costs. ${ }^{20}$ Electronic medical records are the preferred option, as information can be transmitted quickly to wherever it is needed. It will be obvious that good team management and leadership can also reduce transaction costs. Nonetheless, the coordination of care remains more challenging in large compared with small teams, and the costs of this must be balanced against the benefits.

Personal continuity of care is valued by both patients and health care staff, particularly for more serious, psychological or family issues. $^{21,22}$ Continuity of care has been shown to improve health outcomes for patients in some studies, although the wider evidence base remains divided and inconclusive. ${ }^{23}$ Larger team size is known to reduce personal continuity of care, as well as patient satisfaction with access to their preferred caregiver. ${ }^{6,22,24-26}$ On the other hand, rapid access for acute problems tends to be better with larger teams. ${ }^{26}$ The opportunities for specialisation within large teams may also bring about improvements to the quality of care for patients and enhance the range of services that can be provided. Whether these advantages outweigh the disadvantage of loss of personal continuity is unclear and merits further investigation.

\section{Feasibility and sustainability}

Several factors may limit the feasibility and sustainability of extending nursing roles.

First, there is a high capital cost involved in moving from solo GPs to large multidisciplinary teams, and nurses taking on new roles must be trained for this work. The evidence base is small, but research supports the view that clinical guidelines or protocols may help to facilitate the transfer of tasks from doctors to nurses while maintaining quality. ${ }^{27}$ Even so, the pace of service development in England in the 1990s often outstripped the ability of training programs to equip nurses for their new roles. ${ }^{2}$ A persistent challenge is the lack of research into what level of training should be required of a nurse undertaking extended roles in primary care. A systematic review of worldwide research into nurses working as substitutes for GPs found there was wide variation in nurses' job titles and hence their likely qualifications. "Practice nurses", "nurse practitioners", "clinical nurse specialists" and "advanced practice nurses" were all found in such roles. Added to this difficulty is the lack of consistency among countries, and sometimes within countries, in the use of job titles such as "nurse practitioner".

Second, professional regulatory bodies may limit the opportunities for extending nursing roles, and new legislation may be needed to remove unhelpful boundaries. England, for example, has responded by extending prescribing privileges to nurses and other health professionals to expand their role in health care provision. ${ }^{28}$ From spring this year, qualified nurses and pharmacists will be able to prescribe any licensed medicine for any medical condition - with the exception of controlled drugs. ${ }^{29}$

Third, a valid concern which may be raised is who is legally liable when care is delegated from doctors to nurses. In England, each practitioner is liable for the quality of care he or she delivers. 
GPs, as employers, have only to show that they take appropriate steps to ensure nurses are appropriately trained and supervised in their work.

Last, extending nursing roles into the domain of doctors may challenge the professional identity of both practitioners, leading to opposition as people struggle to maintain their traditional professional boundaries. ${ }^{30,31}$ Task delegation from doctors to nurses leaves doctors to manage the more complex patient problems which some do not welcome. ${ }^{32}$ Delegating care to nurses can lead to excessive workloads for nurses unless their numbers are increased and/or simpler tasks are delegated to nurse replacements, such as nurse auxiliaries or health care assistants. ${ }^{33,34}$ Managing these changes takes time and excellent human resource skills.

\section{Limitations in the research}

Most studies of nurse-doctor substitution have included only small numbers of nurses, and very few have considered the potential for practitioner-related variation in outcomes. Patient samples have generally been too small to detect rare, but potentially serious, health outcomes such as missed diagnoses. An added concern is that studies to show the comparability of care by nurses and doctors need to be designed to have the power to assess equivalence, not difference, in outcomes. This has been done in only one study. ${ }^{8}$ The evidence base is further limited by the narrow range of nursing roles that have been rigorously evaluated. Nurses in the UK manage a more diverse range of patient problems than is currently represented in the research literature. As noted above, the potential for cost savings is context dependent and therefore needs to be evaluated on a case-by-case basis.

\section{Conclusions}

Using nurse practitioners to substitute for and complement GPs is a plausible strategy for improving capacity in primary care without compromising the quality of care or health outcomes for patients. However, the capital costs of implementing such change can be high and there may be unintended effects on the continuity and coordination of patient care.

\section{Competing interests}

None identified.

\section{Author details}

Bonnie Sibbald, PhD, FRCGP(Hon), Health Scientist ${ }^{1}$

Miranda G Laurant, MSc, Health Scientist ${ }^{2}$

David Reeves, PhD, Research Fellow (Statistics) ${ }^{1}$

1 National Primary Care Research and Development Centre, University of Manchester, Manchester, UK.

2 Centre for Quality of Care Research (WOK), Ramboud University

Nijmegen, Medical Centre, Nijmegen, The Netherlands.

Correspondence: Bonnie.Sibbald@manchester.ac.uk

\section{References}

1 Department of Health. Statistics for general medical practitioners in England 1993-2003. Statistical bulletin 2004/03. London: HMSO, 2004. Available at: http://www.dh.gov.uk/PublicationsAndStatistics/Publications/PublicationsStatistics/PublicationsStatisticsArticle/fs/en?CONTENT_ID $=4081175 \&$ chk $=$ ydas56 (accessed May 2006)

2 Atkin K, Hirst M, Lunt N, Parker G. The role and self-perceived training needs of nurses employed in general practice: observations from a national census of practice nurses in England and Wales. J Adv Nurs 1994; 20: 46-52.

3 Hirst M, Atkin K, Lunt N. Variations in practice nurses: implications for family health services authorities. Health Soc Care Community 1995; 3: 83-97.
4 McGee $P$, Casteldine G. A survey of specialist and advanced nursing practice in the UK. Br J Nurs 1999; 8: 1074-1078.

5 Baker D, Klein R. Explaining outputs in primary health care: population and practice factors. BMJ 1991; 303: 225-229.

6 Campbell SM, Hann M, Hacker J, et al. Identifying predictors of high quality care in English general practice: observational study. BMJ 2001; 323: 784-787.

7 Myles S, Wyke S, Ibbotson T, et al. Costs and remuneration for cervical screening in general practice in the west of Scotland. J Health Serv Res Policy 1996; 1: 217-223.

8 Laurant M, Reeves D, Hermens R, et al. Substitution of doctors by nurses in primary care. Cochrane Database Syst Rev 2005; (5): CD001271.

9 Laurant M, Hermens R, Braspenning J, et al. Nurse practitioners do not reduce the workload of GPs. BMJ 2004; 328: 927-930.

10 Richardson G. Identifying, evaluating and implementing cost-effective skill mix. J Nurs Manag 1999; 7: 265-270.

11 Family Heart Study Group. Randomised controlled trial evaluating cardiovascular screening and intervention in general practice: principal results of British Family Heart Study. BMJ 1994; 308: 313-320.

12 OXCHECK Study Group. Effectiveness of health checks conducted by nurses in primary care: final results of the OXCHECK study. BMJ 1995; 310: 1099-1104.

13 Baker D, Middleton E. Cervical screening and health inequality in England in the 1990s. J Epidemiol Community Health 2003; 57: 417-453.

14 Middleton $E$, Baker D. Comparison of social distribution of immunisation with measles, mumps and rubella vaccine, England, 1991-2001. BMJ 2003; 326: 854

15 Charlton I, Charlton G, Broomfield J, Mullee MA. Audit of the effect of a nurse run asthma clinic on workload and patient morbidity in general practice. $\mathrm{Br} \mathrm{J}$ Gen Pract 1991; 41: 227-231.

16 Griffin S, Kinmonth A. Systems for routine surveillance for people with diabetes mellitus. The Cochrane Library, Issue 3. Oxford: Update Software, 2002: CD000541.

17 Moher M, Yudkin P, Wright L, et al for the Assessment of Implementation Strategies (ASSIST) Trial Collaborative Group. Cluster randomised controlled trial to compare three methods of promoting secondary prevention of coronary heart disease in primary care. BMJ 2001; 322: 1338-1342.

18 Campbell NC, Thain J, Deans HG, et al. Secondary prevention clinics for coronary heart disease: randomised trial of effect on health. BMJ 1998; 316 1434-1437.

19 Barr DA. The effects of organizational structure on primary care outcomes under managed care. Ann Intern Med 1995; 122: 353-359.

20 Rigby M, Roberts R, Williams J, et al. Integrated record keeping as an essential aspect of a primary care led health service. BMJ 1998; 317: 579-582.

21 Kearley KE, Freeman GK. An exploration of the value of the personal doctorpatient relationship in general practice. Br J Gen Pract 2001; 51: 712-718.

22 Schers $\mathrm{H}$, Webster $\mathrm{S}$, van den Hoogen $\mathrm{H}$, et al. Continuity of care in general practice: a survey of patients' views. Br J Gen Pract 2002; 52: 459-462.

23 Freeman G, Shepperd S, Robinson I, et al. Continuity of care. Report of a scoping exercise for the National Co-ordinating Centre for NHS Service Delivery and Organisation R\&D (NCCSDO). London: NCCSDO, 2001. Available at: http://www.sdo.Ishtm.ac.uk/pdf/coc_scopingexercise_execsumm.pdf (accessed Mar 2006)

24 Baker R. Characteristics of practices, general practitioners and patients related to levels of patients' satisfaction with consultations. Br J Gen Pract 1996; 46: 601-605.

25 Campbell J. The reported availability of general practitioners and the influence of practice list size. Br J Gen Pract 1996; 46: 465-468.

26 Wensing M, Vedsted P, Kersnik J, et al. Patient satisfaction with availability of general practice: an international comparison. Int J Qual Health Care 2002; 14 111-118.

27 Thomas L, Cullen N, McColl E, et al. Guidelines in professions allied to medicine. The Cochrane Library, Issue 3. Oxford: Update Software, 2002: CD000349.

28 Department of Health. Extending independent nurse prescribing within the NHS in England. A guide for implementation. 2nd ed. London: Department of Health Publications, 2004. Available at: http://www.dh.gov.uk/assetRoot/04/ 07/21/77/04072177.pdf (accessed Jun 2006).

29 Department of Health. Nurse and pharmacist prescribing powers extended Press release number 2005/0395. 10 November 2005. Available at: http:// www.dh.gov.uk/PublicationsAndStatistics/PressReleases/PressReleasesNotices/fs/en?CONTENT_ID=4122999\&chk=Mjc1MS (accessed Jun 2006).

30 Dickson N, Pearson $\mathrm{P}$, Emmerson $\mathrm{P}$, et al. Are nurse practitioners merely substitute doctors? Prof Nurse 1996; 11: 325-328.

31 Wilson A, Pearson D, Hassey A. Barriers to developing the nurse practitioner role in primary care - the GP perspective. Fam Pract 2002; 19: 641-646.

32 Charles-Jones H, Latimer J, May C. Transforming general practice: the redistribution of medical work in primary care. Sociol Health IIIn 2003; 25: 71-92.

33 Adams A, Lugsden E, Chase J, et al. Skill-mix changes and work intensification in nursing. Work Employment Society 2000; 14: 541-555.

34 Calpin-Davies PJ. Doctor-nurse substitution: the workforce equation. J Nurs Manag 1999; 7: 71-79.

(Received 31 Jan 2006, accepted 12 Mar 2006) 